\title{
WWORKING PAPERS
}

\section{RESEARCH DEPARTMENT}

WORKING PAPER NO. 13-8

UNDERSTANDING AND MEASURING RISKS

IN AGENCY CMOs

Nicholas Arcidiacono

Federal Reserve Bank of Philadelphia

Larry Cordell

Federal Reserve Bank of Philadelphia

Andrew Davidson

Andrew Davidson \& Company

Alex Levin

Andrew Davidson \& Company

February 2013 


\title{
Understanding and Measuring Risks In Agency CMOs
}

\author{
Nicholas Arcidiacono \\ Larry Cordell \\ Andrew Davidson
}

Alex Levin ${ }^{1}$

\begin{abstract}
The Agency CMO market, an often overlooked corner of mortgage finance, has experienced tremendous growth over the past decade. This paper explains the rationale behind the construction of Agency CMOs, quantifies risks embedded in Agency CMOs using a traditional and a novel approach, and offers valuable lessons learned when interpreting these risk measures. Among these lessons is that to fully understand the risks in Agency CMOs a full bond-by-bond analysis is necessary and that interest rate risk is not the only risk that needs to be considered when conducting risk management with CMOs.
\end{abstract}

\footnotetext{
${ }^{1}$ Cordell is vice president and Arcidiacono is a securities analyst in the Risk Assessment, Data Analysis, and Research (RADAR) Group at the Federal Reserve Bank of Philadelphia. Davidson is CEO and Levin is chief financial engineer at Andrew Davidson \& Company (AD\&Co). We wish to thank Jeremy Brizzi, Mike Hopkins, Yilin Huang, Meredith Williams, and Bill Lang at the Federal Reserve Bank of Philadelphia and members of the Policy Group at the Federal Reserve Board for helpful comments. The views expressed here are those of the authors and do not necessarily reflect those of the Federal Reserve Bank of Philadelphia or Andrew Davidson and Co. This paper is available free of charge at www.philadelphiafed.org/research-and-data/publications/working-papers/.
} 


\section{Introduction}

The market for Agency ${ }^{2}$ collateralized mortgage obligations (CMOs) is not only one of the largest debt markets in the world, it is among the most complex. Despite (or perhaps because of) its complexity, it is not much studied in the academic literature and not much studied outside of the financial firms that issue CMOs. ${ }^{3}$ Yet there are many reasons to study this market. First, between 2000 and 2012, \$4.1 trillion of Agency CMOs were issued, 25\% of the total Agency MBS market. ${ }^{4}$ Second, the market includes literally hundreds of different types of securities formed by carving up, or tranching, Agency MBS principal and interest payments in a myriad of ways. This market is especially important for banks and thrifts, since they hold over \$500 billion of the $\$ 1.2$ trillion of active Agency CMO balances. But perhaps the most important reason for studying the Agency CMO market is because measuring and managing risks in Agency CMOs can be quite complicated, and strong incentives exist to misprice and hide those risks from investors. CMOs range from simple sequential structures to extremely complicated bonds that can be levered bets on the direction of interest rates. CMO deals can contain hundreds of tranches with nested risks that often make traditional classifications insufficient for understanding their underlying risks. More subtly, traditional risk management tools focus on hedging interest rate risk (IRR), but for certain types of CMOs, IRR may not be the major source of risk.

The incentives to misprice and hide risks come from the fact that CMO issuance is not a traditional form of underwriting. The driving force for CMO creation is arbitrage: CMOs will be created only when underwriters see opportunities to buy MBS, structure CMOs, and sell the CMO bonds for more than the price of the underlying MBS plus expenses. Whatever bonds underwriters can't sell, they must hold. The value can come in two main ways: by creating securities that better meet investor objectives or from mispricing that can occur from investors misunderstanding risks. We will show how complexity is a major feature of many CMO structures. We have seen from studies of other structured products markets that complexity and opaqueness often ill serve investor interests. ${ }^{5}$

The paper is organized as follows. In Section II, we describe the workings of the Agency MBS and CMO markets and how CMOs are constructed. In Section III we describe CMO structuring rules and classifications types and show how their risks are often nested, resulting in extremely complicated structures. In Section IV we describe how we gathered our large random sample of Agency CMOs and how we use a combination of the Intex cash flow engine and RiskProfiler valuation software from Andrew Davidson \& Co (AD\&Co) to measure risk in CMOs. In Section V we begin our analysis by describing the traditional approach to IRR analysis used by commercial banks and bank regulators. We first describe the conventional tools used to measure and manage IRR. We show how CMOs with seemingly similar risks can have large variations in risk. In Section VI we describe a method to decompose the value at risk (VaR) in CMOs into component parts of IRR, prepay model

\footnotetext{
${ }^{2}$ Agency refers to mortgage backed securities (MBS) and CMOs whose credit risk is insured by either Ginnie Mae, Fannie Mae or Freddie Mac.

${ }^{3}$ For a notable exception, see Downing, Jaffee and Wallace (2009).

${ }^{4}$ Figures are from Inside Mortgage Finance.

${ }^{5}$ For a discussion of the structured finance CDO market see Cordell, Huang and Williams (2011) and Griffin and Yongjun. For a discussion of the trust preferred CDO market, see Cordell, Hopkins and Huang (2011).
} 
risk, and spread risk. We then show that for many types of CMOs, IRR is not the only, or even the predominant, risk in the CMOs. In Section VII we provide a summary and conclusions.

\section{The Market for Agency MBS and CMOs}

Agency CMOs are created by repackaging the cash flows of agency mortgage-backed securities into multi-class securities. Agency MBS represent pools of mortgage loans that are issued as securities with guarantees of full payment of principal and interest by Ginnie Mae, Fannie Mae, and Freddie Mac. Agency CMOs also have principal and interest guarantees provided by the agencies.

The original CMOs issued in the 1980s were established to transform the 30-year, fixed-rate, levelpay, fully-amortizing, prepayable monthly cash flows of Agency MBS into structures that looked more like corporate bonds. Over time, a wide range of structures have been developed in the CMO market. Today CMO bonds present a rainbow of risks and opportunities to investors. The individual CMO bonds are also referred to as "tranches." While these securities are not subject to credit risk, the types and magnitude of risks to investors are extensive.

From a market value standpoint, the primary risks of the agency MBS that are the source of the CMO bond cash flows are IRR, prepayment risk, and spread risk. IRR represents the change in value from changes in the level or shape of the yield curve. Prepayment risk represents the uncertainty in the timing of the cash flows of the mortgage-backed securities. A portion of prepayment uncertainty is predictable, based on movements in interest rates; another portion is unpredictable and independent of changes in interest rates. Spread risk represents the relative pricing of mortgage and CMO cash flows after adjusting for IRR and prepayment uncertainty. In Section VI we propose a method to decompose the market risk of CMOs into its component parts of IRR, prepayment model risk and spread risk and show how these vary across different CMO types.

From a cash flow standpoint, a CMO can be thought of as a set of rules that split the interest and principal cash flows of the underlying mortgage collateral. As such, the combined risk of the CMO bonds must be fairly close to the risk of the original underlying collateral. Nevertheless, CMO structuring rules allow for the creation of a wide range of bonds with a wide range of risks. Each CMO bond could have more or less risk than the underlying collateral and can also contain risks to investors that are not present in the underlying collateral.

The risks of CMO bonds represent the risks of the underlying mortgage collateral viewed through the prism of the deal structure. For example, the CMO structure can create some bonds that have less IRR, generally because they have a shorter average life or through the use of floating rate coupons. The inevitable result will be that other bonds in the structure will have greater IRR. CMO structures can also create bonds with reduced prepayment uncertainty. This is done by channeling cash flows to bonds according to a pre-determined schedule. Just as with IRR, the creation of more stable bonds necessarily creates bonds with less stable prepayment characteristics.

The basic motivation for the creation of CMOs is arbitrage. For a CMO to be created, an underwriter needs to believe that the total proceeds of the sale of the CMO bonds will exceed the cost of purchasing the collateral, issuance costs, selling expenses, and the risk that the underwriter will not be able to sell certain tranches. This value can generally come from the economic value of creating 
securities that better meet investment objectives or from the economic loss associated with investors misunderstanding the risks of complex instruments.

This last point deserves emphasis, since CMO creation is not a traditional form of underwriting; it is not a brokered transaction. CMO issuance is much different than an underwriter bringing a corporate bond to market where he earns an underwriting fee. In that case the corporation, not the underwriter/dealer, decides if the transaction is economically viable. Underwriters of Agency CMOs therefore benefit from selling securities at prices above fair value, since that increases their profits on the transaction. Overly complex deal structures can obfuscate risks and thus facilitate the sale of bonds at higher prices.

Judging from current holdings, the primary customers of CMOs are banks and thrifts, which between them hold over \$500 billion of the \$1.2 trillion market. Preferences for shorter duration, floating rate assets combined with regulatory restrictions on riskier CMO holdings means that banks and S\&Ls generally prefer lower-risk CMO tranches. It is well known that investors seeking to lower risk pay a premium for their CMOs. Thus, banks and thrifts are at one side of these transactions, with dealers and (mainly) hedge funds taking the offsetting higher risk positions. These institutional features and arrangements make it all the more imperative that CMO investors fully understand their risks.

\section{CMO Structuring Rules and Classifications}

As mentioned, CMOs can be thought of as a set of rules that allocate interest and principal cash flows. As a result, CMOs are split between principal-pay rules and interest-pay rules. The major rules (as of this writing) are described in Table 1. The rules of allocation proscribe the amount and timing of principal and interest payments; in combination, they provide us with the basis for the classification of CMOs that we describe below and summarize in Table 2. Since structures vary in many ways and can be enormously complex, this section lays out the classification scheme for the basic principal and interest rules that embody the vast majority of CMO structures. The goal of this section is to describe the rationale for the creation of these different structures, in particular focusing on their risks and how these risks can be nested. A detailed description of the structuring itself is beyond the scope of this study; several sources listed in the bibliography do an excellent job of this. ${ }^{6}$

\section{a. Features of the Underlying CMO Collateral, the Agency MBS}

CMO principal and interest rules start with the cash flows of the underlying collateral. As mentioned, the raw material for Agency CMOs is the Agency pass-through, so named because the Agency MBS passes through all interest and principal payments to the single structure. After subtracting servicing and guarantee fees, interest is allocated based on the principal balance. Scheduled principal is based on the underlying mortgage contracts and is generally known with a high degree of confidence. Principal coming from prepayments is highly variable and is the main source of risk for fixed-rate Agency pass-throughs, the vast majority of Agency MBS issued.

\footnotetext{
${ }^{6}$ See Crawford (2005), Fabozzi (2007) and Schultz and Ahlgren (2011).
} 


\section{b. Principal Allocation Rules: Sequential Bonds}

Sequential allocation of principal, or time tranching, creates a series of tranches with increasing average lives, with each tranche receiving its principal allocation sequentially, as its name implies. The rationale for this structure is to create securities with shorter or longer average lives than the underlying pass-through, purportedly to satisfy investor demand for short-dated or long-dated cash flows. McManus and Schnure (2006) and Schultz and Ahlgren (2011) argue that the economic rationale for sequentials support the market segmentation, or preferred habitat, theory of the term structure of interest rates. Reinforcing this notion are restrictions imposed on financial institutions that prevent them from mismatching the maturity of assets and liabilities. We will see below that the Federal Reserve's IRR advisory letters instruct banks to "maturity match" their assets and liabilities so as not to be overly exposed to IRR. "Sequentials" were the first CMO structures designed to meet this need and are among the simplest of Agency CMO structures. The effect of this tranching is to design securities with shorter and longer weighted average lives than the underlying MBS.

\section{c. Combined Principal and Interest Allocation Rule: Accrual Bonds}

One way to reduce exposure of early sequentials to risk of slower than expected prepayments, called extension risk, is through the construction of tranches that combine interest payments and coupon payments, transforming interest into principal and creating a bond with no interest payments for a period of time until earlier classes of bonds pay down. The primary rationale for accrual bonds is to provide more cash flows to short-term bonds by allocating interest from the accrual bonds to pay down the short-term bonds instead.

The presence of accruals primarily protects earlier tranches against extension risk, which is important for banks with shorter maturity liabilities or less "sticky" core deposits. But banks are still exposed to risk of faster prepayments, called contraction risk, since this type of structure offers little protection against faster prepayments. According to Fabozzi (2007), this became the motivation for additional structures that offer additional protection against prepayment risk, discussed next.

\section{d. Principal Allocation Rules: PACs, TACs, and ADs}

Additional protection against prepayment risk is offered by a series of structures that further control the allocation of principal in the CMO. Priority allocation of principal means that cash flows are allocated to one bond to maintain a schedule of payments close to a target redemption schedule, with the companion bond absorbing the remaining principal cash flows. The rationale for priority allocation is to create stable cash flows and prepayment protection for investors, with the support bonds absorbing more of the contraction and extension risk of the MBS. The most prevalent types of priority allocation structures are planned amortization class bonds (PACs), targeted amortization class bonds (TACs), or accretion-directed bonds (ADs) and their support (companion) tranches. According to Crawford (2005), the creation of PACs was an attempt to create a corporate bond surrogate out of MBS collateral. Fabozzi (2007) says that the introduction of PAC bonds in 1987 greatly expanded the investor base of CMOs to corporate and institutional investors.

The priority of allocation structure has proved quite popular, as judged by the large number of CMOs that feature this particular structure. PAC bonds can be further enhanced with the addition of PAC bonds that serve as support bonds for the PAC. It is quite common to see several PACs in a single 
CMO deal. A targeted amortization class (TAC) is similar to a one-sided PAC in that it offers protection from contraction risk.

PACs and similarly structured bonds come with substantial risks, however. PAC “collars” are constructed using standard industry conventions to assign prepayment rate assumptions to form the bands around the collar. ${ }^{7}$ However, the initial PAC collar shifts each month as a function of past prepayments. Prepay speeds at or near the high or low ends or above and below the collar will serve to tighten the effective PAC collar for subsequent months, making the initial PAC collar not useful in assessing prepayment protection for a seasoned PAC tranche. As a result, the PAC schedule may not be satisfied even if actual prepayments never fall outside the initial collar. In particular, if the support tranches are paid off early because of faster than expected prepayments, support for the PAC bonds dissipates and the PAC collar tightens.

\section{e. Principal Allocation Rules: Pro Rata Bonds}

The rationale for bonds that allocate principal in a pro rata way is to create bonds with different coupons. Pro rata bonds receive the principal on the same schedule as each other and thus have the same weighted average lives (WALs) under all scenarios. Pro rata bonds are created primarily to implement a variety of interest allocation rules, discussed next.

\section{f. Interest Allocation Rules: Discount and Premium Fixed-Rate Bonds}

Using the pro rata structure, any two (or more) bonds can be created as long as the total amount of interest required equals the amount of interest on the tranche that was split to create the pro rata structure. One way of splitting the coupon income is to create one bond with a higher coupon than the underlying bond or collateral. This would be a premium coupon bond. The remaining interest goes to a lower coupon or discount coupon bond. The main impact of altering coupons in this way is to reallocate prepayment risk.

\section{g. Interest Allocation Rules: Floater and Inverse Floaters}

A common form of pro rata bonds is floaters and their companion bonds, inverse floaters. While one bond has a floating rate, the other bond must move in the opposite direction as rates change so that the sum of their interest payments remains constant. As neither bond can have a negative rate, both bonds have interest rate caps. The rationale for a floating rate mortgage security is obvious from an IRR management perspective. However, Agency MBS is overwhelmingly fixed rate, making the floater/inverse floater structures a response to demand for floating rate, credit-risk-free MBS. Inverse floaters (like interest rate swaps) are economically similar to leveraged investment in an underlying bond.

Risks in inverse floaters are most apparent. In 1992 bank regulators followed by the SEC in 1994 put substantial restrictions on these types of securities for banks and money market funds. (See McManus

\footnotetext{
${ }^{7}$ Quoted prices for CMO transactions are generally based on the Public Securities Association's (PSA) prepayment curve. The PSA curve begins at a $0.20 \%$ annualized conditional prepayment rate (CPR), increasing linearly for 30 months until it reaches 6\% CPR in month 30, after which it is assumed to prepay at the 6\% CPR thereafter. Collars are set at multiples of the PSA above and below the expected rate, e.g., 100 to 300 PSA.
} 
and Schnure (2006) and Davidson, Ho and Lim (1994).) The primary risk of floaters comes from the creation of caps necessary to make the economics of the structure work. However, when floaters and inverse floaters are designed to be components of a support bond for a PAC bond or other bond with a priority of principal structure, the principal payments of the floater will take on all of the risks of the support bond, even as its interest payments float with its index ${ }^{8}$ This makes it clear that to fully understand the risks in any CMO bond, one needs to fully consider the entire CMO structure.

\section{h. Interest Allocation Rules: Strips}

Our final major structural type involves allocating specified percentages of interest and/or principal to securities in a process described as stripping. Often in the case of interest-only (IO) strips, the securities have only a notional principal and receive a return derived from a hypothetical principal balance. The simplest form of IO simply strips all of the interest payments from the MBS, with the companion principal only (PO) strip receiving the full principal allocation. Structured IOs are created from CMO structures where the coupon rates on tranches are set below the MBS coupon rate, generating excess interest to create one or more structured IOs. Another common IO type strips the coupon from a bond with a more stable cash flow, such as a PAC bond, in which case the IO is classified with the security its balance is notional to (in this case a "PAC-IO"). Strips could also be considered an extreme form of pro rata allocation in that the entire principal is allocated to one bond.

As pointed out by Crawford (2005), IO/PO analysis is "notoriously complex.” For this reason, these forms of derivatives are more tightly regulated than other forms of CMOs. IOs and POs can be especially sensitive to even small changes in prepayment models. We will verify the sensitivity of IOs and POs to prepayment model risk in our empirical section.

\section{i. Structural Complexity}

With the large number of different structures possible, dealers have virtually unlimited possibilities to tranche CMOs to allocate principal and interest payments. Table 3 illustrates just how complex these structures have become with a tranche summary of deal FHL 4097. This structure has multiple collateral groups, using many of the structuring techniques described above. In many cases there is nesting of structuring rules so that a PAC bond may be split into sequential bonds and those sequential bonds may be split on a pro rata basis to provide for a variety of interest rate rules, including premium and discount bonds and floater/inverse floater combinations. In the end this structure contains nearly 300 different bonds. Note also the wide variation in coupons and WALs of the securities in each major type. These illustrate a point we will make repeatedly throughout our analysis: to fully understand the risk in an individual CMO requires one to fully understand how these risks are nested within each deal.

\section{j. $\quad$ Summary}

In this section we described three types of principal allocation rules (sequential, priority, and pro rata), three types of interest allocation rules (discount/premium, floater/inverse floater, and IO/PO stripping) and one blended principal and interest rule (interest accrual). While these capture the vast majority of structures in the Agency CMO market, these rules can be nested to create very complex

\footnotetext{
${ }^{8}$ Schultz and Ahlgren (2011, p. 22ff) describe the common construction of a PAC bond with a support bond further subdivided between a floater and inverse floater.
} 
structures, as we see from Table 3. Since these different CMOs can be dependent on each other, understanding the risks of a CMO with its companion bonds is often not enough to enable us to understand all of the risks in a CMO bond. Rather, one must be able to account for how prepayment risk is allocated across the entire CMO collateral group. ${ }^{9}$ To do this requires access to data and software valuation tools that takes into account the entire CMO deal structure. One such system is discussed next.

\section{Data, Sample, and Model Estimation Procedure}

Our research approach involves selecting a large random sample of active CMOs from the market and conducting risk analysis using Andrew Davidson's (AD\&Co’s) RiskProfiler ${ }^{\mathrm{TM}}$ prepayment model and valuation engine. The RiskProfiler valuation engine relies on two data sources: Intex Solutions ${ }^{10}$ (Intex) and eMBS mortgage-backed securities (eMBS). As inputs, Intex and eMBS data enter RiskProfiler for prepayment rate forecasting. After creation of these prepayment forecasts, RiskProfiler applies these forecasts to the Intex cash flow engine, which has coded the rules to allocate principal and interest payments and generate cash flows, then outputs these cash flows back into RiskProfiler for further analysis. In the remainder of this section, we further describe our data sources and how we drew our sample.

\section{a. Data and Software}

Our research primarily uses data and deal structuring algorithms from Intex, a structured finance software and data provider. Intex has modeled the cash flow "waterfalls" for every publicly traded Agency CMO administered by Fannie Mae, Freddie Mac, and Ginnie Mae since $1985 .{ }^{11}$ RiskProfiler integrates these cash flow models when conducting risk and return analysis. Intex also maintains all data needed to do valuations, taken from origination and monthly trustee reports. These data include original and monthly deal and bond balances, bond CUSIPs, CMO tranche types, pool factors, coupons, principal and interest payments for each bond in the deal, and performance information for the underlying collateral. Intex also provides software for entering assumptions about expected prepayments to project cash flows and discount rates to price the bonds.

In addition to cash flow models, RiskProfiler integrates Intex collateral (MBS/pool) amortization terms when conducting risk and return analysis. While amortization metrics are certainly necessary for predicting MBS prepayment behavior, additional descriptive statistics on the loans collateralizing the MBS aid the behavioral prepayment modeling process even further. For example, eMBS provides weighted average LTVs, FICOs, geographic concentrations, property types, loan purposes, and occupancies. The collateral amortization terms derived from Intex, coupled with the "enhanced data" fields derived from eMBS, allow for more accurate prepayment forecasts and, thus, more accurate risk and return measures.

\footnotetext{
${ }^{9}$ A collateral group refers to an individual MBS that is carved up to create CMOs. FHL 4097 has 18 different collateral groups.

${ }^{10}$ More information can be found at www.intex.com.

${ }^{11}$ We did a comparison of Intex issuance balances with an independent source of issuance balances, Inside $M B S / A B S$, and confirmed that the issuance balances were, save for timing, virtually identical.
} 


\section{b. Sample}

For purposes of evaluating the IRR inherent in the Agency CMO market, we drew a random sample of 10,013 Agency CMOs from the Intex population of Agency CMOs, around 20\% of the entire market at the time. After retrieving all outstanding CUSIPs as of November 1, 2010, the Modifiable and Combinable REMICs ${ }^{12}$ (MACRs or, alternatively, Exchanges) and the notional IO certificates were removed. (IOs are sampled separately.) We found a total of 52,747 CMO bonds from 6,541 deals issued since 1985; active balances totaled \$1.26 trillion in November 2010 when we drew our sample. The population is further restricted by removing 12,468 bonds that had balances under $\$ 1$ million or a current balance less than $10 \%$ of the original issuance balance. The intent behind this filter is to remove securities from the population that would be repaid principal too quickly to make IRR analysis meaningful. From the 40,279 remaining bonds, we randomly selected 9,013 CMO bonds.

We also include 1,000 randomly selected interest only (IO) certificates in our sample. Recall that interest-only securities do not have a principal balance, only a notional balance, which is why they don't show up in our initial sample above. But they are a huge part of the Agency CMO market. Intex also includes a total of 17,756 various IOs issued since 1985 with a total notional balance of \$1.5 trillion, around $\$ 600$ billion active as of November 2010. We used a screening approach similar to that used for the CMOs with principal balances by restricting our sample selection rule to those with a notional balance greater than $\$ 1$ million and a pool factor greater than $10 \%$. As shown in Table 4, our final sample includes 10,013 Agency CMO bonds: 9,013 CMOs with principal balances and 1,000 notional interest-only CMOs.

For purposes of our analysis, we have assigned each CMO to a unique classification based on its principal and interest type as classified in Intex. As shown in Table 4, we stratified our sample of 10,013 CMOs into 82 mutually exclusive groups ${ }^{13}$ based on principal and interest type. The definitions of these principal and interest types (as defined by Intex) are in Table 1. For example, within our sample there are 1,529 PACs earning interest at a fixed rate. Each CMO bond is classified by its principal and interest type.

For purposes of relative analysis, our CMO sample was pared down from 82 to 29 distinct CMO types. As shown in Table 4, we filter out CMO types that contained 50 or less CUSIPs within a given type (non-highlighted types). While the number 50 is arbitrary, this filter was applied to remove sparse CMO types because they may not have enough observations to make an accurate depiction of inherent risk. These 29 distinct CMO types serve as our basis for relative risk and return analysis. After examining our initial results, we also eliminated all CMOs with a computed price of two or less. The reason for this is that without this restriction, some of the sample results become dominated by outliers, confounding the analysis. Our final sample was comprised of 9,333 CMOs.

\footnotetext{
${ }^{12}$ Exchanges are simply combined or split REMICs. These securities are effectively duplicates of issued REMIC securities.

${ }^{13}$ We were able to deduce these principal and interest types by separating each CMO's "Intex CMO Type" into its components. Given the complexity of the tranche nesting described earlier, we will show how these classification rules do not fully capture the risks in the CMOs and thus can generate large variation in price changes.
} 


\section{c. Model Estimation Procedure}

As mentioned, all of our model estimation is conducted using AD\&Co's RiskProfiler. Our pricing date is November 26, 2010. For each of our CMOs we begin by assuming an option-adjusted spread (OAS) equal to " 0 ” and compute effective durations and convexities, key-rate durations and convexities, vegas, prices, sensitivities to OAS, and refinancing and turnover scales of the prepayment model. We do our runs with 500 Monte Carlo simulations. ${ }^{14}$

To improve the accuracy of prepayment modeling, we employ the RiskProfiler feature called "enhanced multipliers." This term refers to the use of seven data fields calculated with pool-level distributions taken from the eMBS data: MBS pools' average (weighted by balance) FICO credit score, original LTV, loan size, loan purpose, property type, occupancy, and state. The enhanced data set first became available in 2003 when Fannie Mae and Freddie Mac started publishing the data. The enhanced data alter the refinancing multiplier and the turnover multiplier of our model, which we will describe in our $\mathrm{VaR}$ analysis below.

\section{Market Value Changes to Interest Rate Shocks}

To lay out expectations for banking organizations regarding IRR management, financial regulators ${ }^{15}$ have published interagency advisories. The most recent guidance is found in Supervision and Regulation (SR) letter 10-1 and this letter's related guidance, SR 12-2. ${ }^{16}$ These SR letters elaborate on a number of required measurement methodologies. One of the mandated approaches for quantifying IRR exposure is an economic-value-based approach ${ }^{17}$ that measures the change of an institution's assets and liabilities due to defined movements in interest rates. ${ }^{18}$

The economic value of equity is defined as the difference between the economic value of an institution's assets and the economic value of its liabilities. Calculating the economic value of equity (EVE) under various interest rate scenarios is a detailed forward-looking task that requires re-pricing assumptions to be made over a long-term horizon. Additionally, when calculating the EVE, an institution captures all future cash flows expected from existing assets and liabilities. An

\footnotetext{
${ }^{14}$ The assumption of a " 0 " OAS is used in the absence of initial price information. We did gather modeled prices from an independent vendor, but this generated a considerable number of outlier values. Since our study is a risk analysis, and not a pricing analysis per se, we use our 0 OAS with the understanding that it adds some variability to the price changes. We correct for this to a large extent by eliminating some observations where the assumption is most severely violated.

${ }^{15}$ The financial regulators consist of the Board of Governors of the Federal Reserve System (FRB), the Federal Deposit Insurance Corporation (FDIC), the National Credit Union Administration (NCUA), the Office of the Comptroller of the Currency (OCC), the Office of Thrift Supervision (OTS), and the Federal Financial Institutions Examination Council (FFIEC) State Liaison Committee (collectively, the regulators).

${ }^{16}$ SR letters are numbered by year and the order in which they are issued within the year. SR 10-1 is located at http://www.ffiec.gov/pdf/pr010710.pdf. SR 12-2 is located at http://www.federalreserve.gov/bankinforeg/srletters/sr1202.pdf.

${ }^{17}$ This economic value approach can be referred to as the economic value of equity (EVE), net economic value (NEV), net portfolio value (NPV), or market value of portfolio equity (MVPE) approach.

${ }^{18}$ These instantaneous interest rate movements can be parallel (i.e., every tenor along the yield curve shifts upward or downward by the same amount) or non-parallel in nature. The advisory also suggests shifts of \pm 300 and \pm 400 basis points as examples of meaningful stress scenarios.
} 
asset/liability committee (ALCO) routinely prepares reports for bank management that details the institution's IRR exposures given various parallel and non-parallel interest rate simulations.

Our analysis begins by replicating the standard approach of the EVE method, i.e., re-pricing Agency CMOs given a defined instantaneous movement of interest rates. Naturally, as interest rates shift, future cash flows (principal and interest) and discounting factors also change. As shown in Table 5, we evaluate the computed price changes of our 29 CMO classification types given a +200 basis point parallel shift of the yield curve. The +200 shift is of particular importance to our analysis because the magnitude (200bp) of this adverse rate shift is both commonly used in current supervisory practice and a plausible future scenario given the current low level of interest rates. ${ }^{19}$ As shown in Table 5, a number of conclusions can be deduced from the market value changes across various CMO types. First, we can visualize the directional re-pricing risk for various CMO types and the "market" (ALL category). The CMO "market" will decrease by an average of $7.1 \%$ given the fundamentally negative relationship between interest rates and price movements of fixed income instruments. However, given the financial engineering efforts behind CMO creation, various CMO classifications will actually increase in value given an increase in interest rates. For example, the "Notional Fixed Interest Only" bonds increase by an average of $46.9 \% .^{20}$

Second, relative relationships on average can be established. Principal allocation types can be compared on average: "Support Fixed" types are riskier than their "PAC Fixed" counterparts, with an average decline in market value of $9.1 \%$ and $7.2 \%$, respectively. Additionally, typically short WAL “Accretion Directed Fixed” bonds are less risky than their longer "Z Accrual Bond Fixed” counterparts. Interest allocation types can be compared with ease: across the board, floating rate types are less risky than their fixed or inverse IO counterparts, since floaters' interest rate moves directionally with market rates. Also, POs and their strip IO counterparts experience significant declines and increases on average in an adverse interest rate shift scenario.

Last, and perhaps most important, these classifications show significant dispersion within their given classifications. These provide strong evidence that to fully understand the risk of CMOs, one must conduct cash flow analysis on a bond-by-bond basis and not rely solely on classifications for risk levels. In light of principal rule nesting, CMO structures can be very complex in nature. While classifications are useful in determining the directionality of risk, tranche-level cash flow analysis must be used to determine the magnitude of applicable risk.

\section{VI. $\quad$ Value at Risk (VaR) and Risk Decomposition}

The previous section described the standard approach to IRR measurement used by regulators and managers at financial institutions responsible for asset liability management (ALM). The approach exclusively focuses on being properly hedged for IRR. In this section we describe how IRR is not the only, and in some cases not even the major, risk facing short-term ALM. We first describe the

\footnotetext{
${ }^{19}$ Interest rate shocks of +400 and -100 bps were also conducted, available from the authors upon request.

${ }^{20}$ The price increase of this classification is due to the WAL extension of these bonds. As the prevailing interest rates increase, the mortgages collateralizing these IOs don't prepay as quickly, thus extending the bond's WAL and consequently increasing the amount of cash flows payable to the IO holder. This increase in cash flows is enough to offset the rise in discount factors associated with an increase in interest rates and consequently result in a price increase
} 
methodology for decomposing risks in interest-sensitive mortgage assets, explain modeling assumptions needed to make the models work, and then show results for our CMO sample.

a. The Methodology

We now apply the short-term IRR assessment framework, known as the "Delta-Gamma” method, to the case of multiple risk factors. Let's assume that our instrument (strategy, portfolio) is exposed to a factor $x$ having the known standard deviation $\sigma$ over a user-selected time horizon. First, we measure Duration $\left(D=-\frac{1}{P} \frac{d P}{d x}\right)$ and Convexity $\left(C=-\frac{1}{P} \frac{d^{2} P}{d x^{2}}\right)$ of our instrument with respect to $x$. Then, we postulate that price $P(x)$ is quadratic in $x$ :

$$
P=P_{0}\left(1-D x+0.5 C x^{2}\right)
$$

For each CMO, we propose computing an 84\%-confidence short-term VaR metric (denoted $\mathrm{VaR}_{84}$ hereinafter) with its separation into IRR, prepayment model risk, and pricing spread, or OAS, risk. The $\mathrm{VaR}$ is computed using a theoretical approach rather than an empirical time series of prices. ${ }^{21}$

In Section II we described the three types of primary risks from a market value perspective. A further elaboration of these risks is as follows:

1. Interest rate risk includes risks of changing interest-rate level, curve steepness, and volatility. This risk can usually be hedged using traditional derivatives.

2. Prepay model risk includes risks of refinancing and turnover biases, i.e., changing the scales of prepayment modeling views. This risk can, and should, be managed, as we explain further.

3. Spread risk is the risk of changing the discount spread, not already explained by factors $1-2$ above. Note that this is a technical factor linked to financing and liquidity of the MBS market and not to its fundamental economics. It is usually difficult to hedge, but it is the smallest of the three.

Perhaps the least known aspect of our risk decomposition is the recognition of prepay model risk, separately and independently from interest rates and discount spreads. The more traditional approach in the previous section could be extended by separating total risk into IRR and "spread" OAS risk. In this traditional classification, spread lacks economic understanding. For example, a holder of an IO and the matching PO effectively holds an asset and its hedge. Whereas both IOs and POs have very volatile pricing spreads (regularly swinging by hundreds of basis points), their prices remain negatively correlated.

If we continue to analyze IOs and POs, we can come to understand that the likely cause of volatility, above and beyond interest rates, is changes in prepayment sentiment. Any acceleration in prepay outlook will depress IO prices and elevate PO prices; a deceleration would do the opposite. The $\mathrm{IO} / \mathrm{PO}$ case is a strong, but not the only, example of leveraged prepay model risk. In fact, many CMO tranches are designed synthetically, as discussed above, by separating a fixed-rate tranche into a floater and an inverse floater, or a par tranche into a discount tranche and an IO. These examples

\footnotetext{
${ }^{21}$ While useful, the knowledge of total empirical VaR cannot help a risk manager to do the work of hedging or diversifying financial risks.
} 
show that a risk model would greatly benefit from separating the traditional spread risk into economically recognizable prepayment model risk and the pricing spread merely reflecting market technical conditions.

In order to compute the total VaR and its constituent components, we first compute CMO exposures (durations and convexities) to the selected risk factors. We then multiply those measures by one standard deviation of each factor assessed for a short investment horizon and apply relevant VaR formulas. For example, if the convexity terms are negligible and the factors are independent, the total $84 \%$-confidence VaR will be equal to $V A R_{84}=\sqrt{D_{1}^{2} \sigma_{1}^{2}+D_{2}^{2} \sigma_{2}^{2}+\cdots}$ where $D$ s denote durations and Sigmas denote standard deviations, for factors 1 , 2, etc. Obviously, this approach requires us to know both $D$ s and sigmas.

If convexity terms cannot be ignored, then the VaR formula is modified as:

$$
V A R_{84}=-0.5 \sum_{i} C_{i} \sigma_{i}^{2}+\sqrt{\sum_{i} D_{i}^{2} \sigma_{i}^{2}+0.5 C_{i}^{2} \sigma_{i}^{4}}
$$

This metric retains its $84 \%$ confidence interpretation approximately if the duration term dominates the convexity term. Regarding one factor at a time (i.e., setting all other Sigmas to zero), we can compute constituent VaR contributions, i.e., “decompose” the total risk. This metric is important for both informative purposes and developing a risk management strategy.

The volatility pattern of each factor can be determined from market observations. For example, one can determine the short-term interest rate volatility (and volatility of that volatility) using traded swaptions. Volatility of the shape can be assessed using historical yield-curve data. Volatility of prepayment modeling scales can be found empirically using AD\&Co’s so-called risk-neutral prepayment model, discussed below. Finally, volatility of the residual pricing spread may be more difficult to find, but this is often the smallest factor to worry about.

\section{b. The Role of Risk-Neutral Prepayment Modeling}

The key idea that differentiates this work from some others is the use of a risk-neutral prepay model. It is employed in a number of assumptions we make, such as computing the Greeks or quantification of risk factors, including their volatility and correlation.

The concept is introduced by Levin and Davidson (2005). They argue that the MBS markets price prepay model risks as evidenced by the fact that OAS level varies across instruments. They proved that one can include the price of prepay model risk into an OAS model by altering prepayment scales, thereby making the prepayment model "risk-neutral." The Levin-Davidson risk model is twodimensional, with refinancing and housing turnover considered as separate risk factors, possibly correlated.

There exist two main practical options for calibrating prepay risk neutrality. The first option is to start with an empirical prepayment ("physical”) model and change its scales so that all "to be announced" (TBA) ${ }^{22}$ MBS are priced flat to the respective agency debenture curve. In essence, this

\footnotetext{
${ }^{22}$ TBA is a term used to describe a forward mortgage-backed securities trade. Pass-through securities issued by Freddie Mac, Fannie Mae, and Ginnie Mae trade in the TBA market. The term TBA is derived from the fact that the
} 
method postulates investors' indifference to buying GSE-backed TBAs or GSE-issued debts as long as prepayment model risk is fully priced in the former.

The other option is to equate OAS of stripped MBS, IOs, and POs. Each of these two choices has pluses and minuses. The TBA-based method is easy to automate and is equipped with reliable pricing entries, but it relies on the assumption that TBAs have the same credit and liquidity as the debentures. The IO/PO OAS parity method is free of this assumption, but many input prices need to be derived.

Practical applications of the risk-neutral prepayment model have a pronounced effect on valuation and risk assessment. First, we start with using a reliable OAS level adjusted for prepay model risk (denoted prOAS) to price all agency MBS, regardless of their classification. For this project, we used prOAS $=0$ to Libor for all CMOs we analyzed. Clearly, such an assumption cannot be made when using a physical prepayment model, since we expect instruments with leveraged prepayment risk (IO, $\mathrm{PO}$, inverse floaters) to have substantially different OASs. ${ }^{23}$

Second, OAS valuation under a risk-neutral prepayment model alters interest rate sensitivities and other Greeks. Often, the risk-neutral refinancing scale is found to be above 1.0. This is related to the risk preference of premium MBS investors who demand compensation for bearing the risk that the future refinancing can be faster than an empirical model projects (which has a negative effect on return). Likewise, investors in discount MBS may experience market losses if the model overstates the strength of housing turnover; the risk-neutral turnover scale is often below 1.0. Naturally, such a model will deliver shorter effective durations for premium MBS and longer for discounts.

Third, our model calibration process establishes current prepayment scales that become risk factors in our analysis. AD\&Co has been collecting the data using this method since 2004. Figure 1 depicts AD\&Co’s risk-neutral refinancing and turnover scales for the first nine months of $2010 .{ }^{24}$ Not only does Figure 1 depict the randomness of both scales, it also allows us to measure its empirical volatility, mean reversion, and correlation. This information is necessary to conduct the VaR calculations, as explained in detail below.

\section{c. The Time Aspect of Risk}

If a risk factor follows the pattern of a Brownian motion, its standard deviation grows in proportion to the square-root of time (ignoring convexity). It is known, however, that interest rates are stable and, hence, mean reverting, albeit at a slow pace. Other factors may revert even faster.

One example is prepayment model risk. Any announcement of government activity related to credit eligibility or economic policies can swing prepay outlook nowadays. As seen in Figure 1, AD\&Co’s risk-neutral refinancing and turnover scales are strongly mean reverting.

actual mortgage-backed security that will be delivered to fulfill a TBA trade is not designated at the time the trade is made. The securities are "to be announced" prior to the established trade settlement date.

${ }^{23}$ We collected prices provided by a leading vendor to do the analysis as an alternative to setting prOAS $=0$ and using the prices to solve for the OAS. We abandoned this after we observed many results where the OASs approached levels that did not appear to make sense. This is likely due to vendors providing pricing information across the entire market and not addressing data issues due to the sheer size of the pricing exercise. Setting prOAS = 0 avoided this problem and generated more reasonable results overall.

${ }^{24} \mathrm{AD} \& \mathrm{Co}$ had not changed the physical prepayment model during that period. 
Assuming a linear, single-dimensional Ornstein-Uhlenbeck pattern, we can connect standard deviation $\sigma(t)$ at horizon $t$ (in years) to the annualized volatility $\sigma(1)$ as

$$
\sigma(t)=\sigma(1)\left(\frac{1-e^{-2 a t}}{1-e^{-2 a}}\right)^{1 / 2}
$$

where $a$ is the mean reversion factor per year. Hence, if volatility is quoted in an annual form, one can easily assess standard deviation in 1 week, 1 month, etc.

If mean reversion $a$ is $0, \sigma(t)$ becomes proportional to $\sqrt{t}$ (after taking the limit to resolve a $0 / 0$ uncertainty). On the other hand, if $a$ is infinite, then $\sigma(t)=\sigma(1)$ for any $t>0$. Figure 2 depicts the $\sigma(t) / \sigma(1)$ ratio as a function of $a$.

As seen, the stronger the mean reversion is, the closer the standard deviation becomes to a mathematical step function. This observation explains the different weights of factors contributing to the total VaR computed over different horizons.

\section{d. Volatility Assumptions}

In order for the theoretical VaR method to work, not only do we need to compute Deltas and Gammas, but we also have to know the stochastic properties of the risk factors: volatilities, mean reversions, and mutual correlations. Below we explain the sources of this information.

\section{i. Interest Rate Risk (IRR)}

Volatility of the parallel change pattern can be easily implied by the swaption volatility matrix. AD\&Co has developed a calibration method that best approximates the swaption market. It finds the best short-rate volatility parameter and mean reversion constant for a single-factor term structure model. ${ }^{25}$ Note that of the term structure models imply a strictly parallel shift in the yield curve (expect in the case of zero mean reversion for the Hull-White model we use). In most cases, using a meanreverting model leads to a volatility structure falling with maturity.

Volatility of the slope change can be found from empirical observation. One way is to find the second largest principal component of the curve moves (see Levin (2002) and James and Webber (2000)). Note that the propensity to twist changes with time. For example, in 2007 all rates were falling while the shape of the curve remained essentially flat. In 2008-2009, short rates declined more than long rates. Furthermore, with the Fed's intention not to raise rates, the curve's shape can easily change in either direction.

Our analysis is based on the following pattern of steepening/flattening (numbers in \%):

\begin{tabular}{|ccccc|}
\hline $1 \mathrm{mo}-1 \mathrm{yr}$ & $2 \mathrm{yr}-3 \mathrm{yr}$ & $4 \mathrm{yr}-5 \mathrm{yr}$ & $7 \mathrm{yr}-10 \mathrm{yr}$ & $15 \mathrm{yr}-30 \mathrm{yr}$ \\
\hline-0.7 & -0.3 & 0 & 0.3 & 0.7 \\
\hline
\end{tabular}

Volatility of interest rate volatility can be measured using equivalent volatility constants observed over historical intervals.

\footnotetext{
${ }^{25}$ For our estimation, we use the Hull-White (1990) single-factor model.
} 


\section{ii. Prepayment Model Risk}

We have already introduced the concept of measuring prepay model risk. We intend to quantify it via calibrating the prepay model to the TBA/agency debt parity and measuring the stochastic properties of thus obtained refinancing scales and turnover scales. We refer to Figure 1 as an example of relevant empirical data. Aside from both scales exhibiting strong mean reversion, they are negatively correlated.

\section{iii. Spread (OAS level) Risk}

This is the risk of the OAS level changing after all economic factors have been accounted for. It is the residual risk that reflects the volatility of technical factors (financing and liquidity) both for the CMO market as a whole and for particular tranche types. Note that this risk, while certainly existing, should be deemed free of contributions made by changing prepayment views; those are absorbed by the prepayment model risk factor. Hence, we expect spread risk to be generally less important for Agency CMOs than a traditional risk analysis would show. Table 6 tabulates all volatility assumptions and the correlation matrix we used for the market date of analysis. It also computes standard deviations for the 1-week and 3-month horizons.

As explained above, strong mean reversion makes the standard deviation resemble a step function. For example, uncertainties of prepayment scales are of the same order of magnitude whether we use a 1-week horizon or a 3-month horizon. In contrast, no-mean-reverting factors or weekly meanreverting factors follow the famous square root of time rule: the risk in three months is almost four times greater than the risk in one week.

\section{e. Overall Results}

After computing VaRs for our sample of 9,333 bonds, we aggregated them into two metrics: average and worst. The worst VaR is computed as the average plus two standard deviations within each CMO type and each risk type. Results sorted by total VaR are shown in Tables 7 (1-week horizon) and 8 (3month horizon) using signal-coded tables to denote the importance of each effect.

\section{i. $\quad$ Risk Ranking at a Glance}

As Tables 7 and 8 show, IOs have the highest overall risk followed by POs, inverses, Z-accruals, PACs and supports and sequentials. Not surprisingly, direct floaters are the least risky. Both IOs and POs are strongly exposed to prepay model risk. For IOs, this is the leading risk contributor for the 1-week horizon and remains essential for the 3-month horizon. For POs, prepay model risk is comparable in magnitude to IRR.

The inverse floater is the bronze medal holder in our risk ranking. It can be shown that the risk of an inverse floater is that of the underlying fixed-rate tranche (leveraged) plus a PO, which increases the leverage. In some sense, inverse floaters look like IOs on our chart, just with much smaller risks measured relative to its much higher base value.

Z-accruals are next in our risk ranking. These are purposely deferred, usually long, bonds naturally exposed to the selection of a discount factor. This factor is comparable to the prepay model risk but ranks below IRR. 
Support bonds are about as risky as PACs or sequentials. As we would expect, pass-through tranches are among the least risky bonds. While their OAS exposure is relatively large, the OAS level itself is likely to be somewhat more stable than that for exotic CMOs.

\section{ii. The Role of CMO Classification}

The Worst/Avg scales show how much one can pinpoint the risk of a tranche by merely knowing its type. The closer this ratio is to 1.0, the more important the CMO classification is. The higher the ratio, the larger the risk dispersion within the group.

Our analysis shows that using our CMO classification reduces risk dispersion. For example, using the 1-month horizon table, we see that the Worst/Avg ratio would be 4.15 if we did not know the CMO type (the "ALL” row). Once we know the type, the ratio gets down mostly to the 2-2.5 range. Nevertheless, within most of the groups, there still exists substantial uncertainty about the risk. This points to the necessity of an individual tranche-by-tranche analysis as pinpointing risk. Using just the CMO type is not enough.

Interestingly, risk for pass-through tranches is dispersed more narrowly than risk for other types. This is expected because these bonds differ only in coupon and age but have no structural differences. Supports and sequentials, on the other hand, differ in the attained state of their deal structures, in addition to coupon and age.

\section{iii. The Role of IRR Hedging}

One immediate risk management lesson we learn from this analysis is that hedging the IRR, while useful and necessary, may not reduce the overall short-term risk as much as many practitioners hope. For example, the first line in Table 7 shows that the average weekly VaR is about $9.5 \%$ for IOs stripped off fixed-rate sequential tranches. If we perfectly hedge the IRR, we can bring VaR down to about $7.6 \%$, or $20 \%$ lower. We view this as a small reduction for the amount of attention the IRR management is traditionally getting. Managing risk for IOs and POs requires steps toward the reduction of dependence on prepayment views. For example, managers of mortgage servicing rights (MSRs) that deal with an IO-like business line usually realize this, to some extent.

The “Minus IRR” column in Tables 7 and 8 quantifies the role of a full IRR removal, as

$$
\text { IRR Reduction }=\text { VaR(no IRR) } / \text { VaR(Total })-1 .
$$

This is a negative number, stated as a percentage. The zero level means no risk reduction effect, while the $-100 \%$ level is equivalent to perfect risk elimination. The reduction, measured on an average basis, is seen to be rather modest for the 1-week horizon, and more essential, but far from perfect, for the 3-month horizon. Factor independence and the associated Pythagorean rule of VaR subtraction explain why even removing a dominant factor does not necessarily reduce the residual risk to a negligible level.

\section{iv. The Role of Horizon}

Let us recall that the Delta-Gamma method assumes a knowledge of those Greeks for risk assessment. The 3-month period is the longest time horizon we would trust with our method, since the accuracy of current Greeks drops with the extension of the time horizon. 
When moving from a 1-week horizon to a 3-month horizon, we changed the signal code so that the risk ranges are commensurate with the longer horizon. The critical difference between Tables 7 and 8 is the role of prepay model risk (relative to other factors). As mentioned, prepayment scales are strongly mean reverting and front loaded, unlike interest rates. The 3-month overall risk is primarily IRR. But we should reiterate that this does not mean that a perfect IRR hedge would make the remaining risk negligible.

\section{Summary and Conclusions}

In this paper we attempt to do several things. First, we describe the process of Agency CMO creation; explain why it does not represent a traditional form of underwriting; and explain why it is important for investors to fully understand their risks, especially as these CMOs increase in complexity. Second, we describe how we drew our sample of CMOs and our methodology for valuing Agency CMOs with Andrew Davidson's RiskProfiler engine and Intex. Third, we describe traditional ways in which financial firms measure IRR and show the wide variation in market values for different types of CMOs for a 200 basis point increase in interest rates. Finally, we describe a value at risk (VaR) approach to decomposing the risk of CMOs into its component parts of IRR, prepayment model risk, and spread risk and show how these vary across different CMO types.

Our conclusions are as follows. First, by carving up Agency MBS risk in many ways, Agency CMOs offer the opportunity for investors to better manage risks in an Agency MBS but only if investors fully understand the risks. A first thing to understand is that the driving force of Agency CMO issuance is arbitrage, which can be achieved either by creating securities that better meet investor objectives or from the economic loss associated with investors misunderstanding risks. We also show how complex CMO deal structures can become, making it essential that investors fully understand the risks of the CMOs they purchase. Second, we show that knowledge of CMO type reduces the uncertainty about its risks, but the outcomes are still too wide to pinpoint a risk level. It is necessary to do individual bond-by-bond analysis, taking into account nested risks not obvious from traditional bond classifications. Third, understanding that the risks in CMOs go beyond traditional measures of IRR, we show that decomposing the total risk of Agency CMOs into its component parts shows that IRR is not always the leading risk factor. In particular, prepayment model risk can be significant in IOs, POs, inverse floaters, and some other CMO structures, especially over short investment horizons. Prepayment risk can be controlled and possibly hedged, but not with traditional tools. Even over longer horizons of three months or more, hedging IRR may not make the total risk small.

The sum total of our findings leads us to conclude that investors need to be fully informed of risks in Agency CMOs before investing in them, and that requires sophisticated bond-by-bond cash flow analysis of the type described in this paper. There is a decided "buyer beware" quality to Agency CMOs that is not found in more traditionally underwritten securities. 


\section{$\underline{\text { References }}$}

Cordell, Larry, Michael Hopkins, and Yilin Huang. “The Trust Preferred CDO Market: From Start to (Expected) Finish,” Federal Reserve Bank of Philadelphia Working Paper 11-22 (2011).

Cordell, Larry, Yilin Huang and Meredith Williams. "Collateral Damage: Sizing and Assessing the Subprime CDO Crisis,” Federal Reserve Bank of Philadelphia Working Paper 11-30/R (2011).

Crawford, Alexander, 2005, “Collateralized Mortgage Obligations,” in The Handbook of Fixed Income Securities, New York: McGraw Hill, pp. 541-578.

Davidson, Andrew, Thomas S. Y. Ho and Yung C. Lim, 1994, Collateralized Mortgage Obligations. Chicago, IL: Probus Publishing.

Downing, Chris, Dwight Jaffee, and Nancy Wallace, 2009, “Is the Market for Mortgage-Backed Securities a Market for Lemons?” Review of Financial Studies. Volume 22, pp. 2457-94.

Fabozzi, Franklin J., 2007, Fixed Income Analysis. New York: John Wiley and Sons.

Griffin, John M., and Dragon Yongjun (2012), “Did Subjectivity Play a Role in CDO Credit Ratings?” Journal of Finance Volume 67, pp. 1293 - 1328.

Hayre, Lakhbir, 1999, Guide to Mortgage-Backed Securities. Solomon Smith Barney (March), pp. 162.

Hull, John, and Allen White, 1990, "Pricing Interest-Rate Derivative Securities," Review of Financial Studies. Volume 3(4), pp. 573:592.

James, J., and N. Webber, 2000, Interest Rate Modeling, New York: Wiley.

Levin, Alex, and Andrew Davidson, "Prepayment Risk-and-Option-Adjusted Valuation of MBS," Journal of Portfolio Management, Volume 31, No. 4, Summer 2005, pp. 73-85.

Levin, Alex, 2002, “A Linearization Approach in Modeling Quasi-Affine Coupon Rate Term Structure and Related Derivatives,” in M. Avellaneda (ed.), Quantitative Analysis of Financial Markets, pp. 199 - 221.

McManus, Douglas A. and Calvin Schnure, 2006, "What Drives REMIC Security Design? The Evolution of Structured Mortgage-Backed Security Design,” Internal Freddie Mac manuscript (December 29).

Schultz, Glenn and Randy Ahlgren, 2011, "Understanding Real Estate Mortgage Investment Conduits (REMICs),” Wells Fargo Structured Products Research (December 21), pp. 1-41. 
Table 1

List of Principal and Interest Types in Agency CMOs*

\begin{tabular}{|c|c|c|}
\hline \multicolumn{3}{|c|}{ Principal Types } \\
\hline Abbr. & Full Name & Description \\
\hline AD & Accretion Directed & $\begin{array}{l}\text { Receives principal payments from the accrued and unpaid interest on one or more Accrual or } \\
\text { Partial Accrual classes. It also may receive principal payments from principal paid on the } \\
\text { underlying securities or other assets of the related series trust. }\end{array}$ \\
\hline AS & Accelerating Senior & $\begin{array}{l}\text { For agency deals with NAS (non-accelerating senior) tranches, all other tranches within that } \\
\text { group, which can be expected to be absorb the prepayment volatility inherent in the creation of a } \\
\text { less-prepayment-sensitive NAS tranche }\end{array}$ \\
\hline BUL & Bullet Maturity & $\begin{array}{l}\text { Principal is scheduled to be received in one payment at tranche maturity (generally applies to } \\
\text { master trust deals) }\end{array}$ \\
\hline CALL & Callable & Callable class \\
\hline NAS & Non-Accelerating Senior & $\begin{array}{l}\text { Senior tranche which receives scheduled and prepaid principal according to shifting interest } \\
\text { provisions, as a way of limiting the effect of prepayments on that tranche }\end{array}$ \\
\hline NTL & Notional & $\begin{array}{l}\text { Has no principal balance and bears interest on its notional principal balance. The notional } \\
\text { principal balance is used to determine interest distributions on an Interest Only class that is not } \\
\text { entitled to principal. }\end{array}$ \\
\hline PAC & $\begin{array}{l}\text { Planned Amortization } \\
\text { Class }\end{array}$ & $\begin{array}{l}\text { Is designed to receive principal payments (or has a notional principal balance that is designed to } \\
\text { decline) using a predetermined principal balance schedule (a 'Planned Balance'). The schedule is } \\
\text { derived by assuming two constant prepayment rates for the mortgage loans backing the related } \\
\text { underlying securities. These two rates are the endpoints for the 'structuring range' of the PAC } \\
\text { classes. }\end{array}$ \\
\hline PACn & $\begin{array}{l}\text { Planned Amortization } \\
\text { Class } n\end{array}$ & $\begin{array}{l}\text { Is designed to receive principal payments (or has a notional principal balance that is designed to } \\
\text { decline) using a predetermined principal balance schedule (a 'Planned Balance') as part of a } \\
\text { sequence of PACs from } 1 \text { to } n \text {. The schedule is derived by assuming two constant prepayment } \\
\text { rates for the mortgage loans backing the related underlying securities. These two rates are the } \\
\text { endpoints for the 'structuring range' of the PAC classes for this nth priority among the series of } \\
\text { PACs. PAC groupings can go as high as four in number. }\end{array}$ \\
\hline PT & Pass-Through & $\begin{array}{l}\text { Is designed to receive principal payments in direct relation to actual or scheduled payments on } \\
\text { the underlying securities, but is not a Strip class. }\end{array}$ \\
\hline SEQ & Sequential Pay & $\begin{array}{l}\text { Receives principal payments in a prescribed sequence but without a predetermined schedule. In } \\
\text { most cases, it receives payments of principal continuously from the First Distribution Date until the } \\
\text { class is retired. A single class that receives principal payments before or after all other classes in } \\
\text { the same series of Certificates may be identified as a Sequential Pay class. }\end{array}$ \\
\hline SPP & $\begin{array}{l}\text { Shifting Payment } \\
\text { Percentage }\end{array}$ & $\begin{array}{l}\text { Classes that receive principal attributable to prepayments on the underlying Mortgages in a } \\
\text { different manner than principal attributable to scheduled payments and/or in shifting proportions } \\
\text { over time }\end{array}$ \\
\hline STP & Pro-Rata Strip & $\begin{array}{l}\text { Receives a constant proportion, or 'strip,' of the principal payments on the underlying securities or } \\
\text { other assets of the series trust. }\end{array}$ \\
\hline SUP & Support & $\begin{array}{l}\text { Receives principal payments (or has a notional principal balance that declines) on any } \\
\text { Distribution Date only if scheduled payments have been made on specified PAC, TAC and/or } \\
\text { Scheduled classes (except that it may also receive principal payments from the accrued and } \\
\text { unpaid interest on specified Accrual or Partial Accrual classes). }\end{array}$ \\
\hline TAC & Targeted Amortization & $\begin{array}{l}\text { Is designed to receive principal payments (or has a notional principal balance that is designed to } \\
\text { decline) using a predetermined principal balance schedule (a 'Targeted Balance'). In most cases, } \\
\text { the schedule is derived by assuming a single constant prepayment rate for the mortgage loans } \\
\text { backing the related underlying securities. }\end{array}$ \\
\hline XAC & Index Allocation & Has a principal payment allocation that is based on the value of an index. \\
\hline $\mathbf{Z}$ & Accrual & $\begin{array}{l}\text { Accretes the amount of accrued interest otherwise distributable on this class. This accreted } \\
\text { amount will be added as principal to the principal balance of the class on each applicable } \\
\text { Distribution Date. Accretion may continue until some specified event has occurred or until the } \\
\text { Accrual class is retired }\end{array}$ \\
\hline \multicolumn{3}{|c|}{ Interest Types } \\
\hline Abbr. & Full Name & Description \\
\hline FIX & Fixed-Rate & Has an interest rate that is Fixed throughout the life of the class. \\
\hline FLT & Floating-Rate & $\begin{array}{l}\text { Has an interest rate that resets periodically based upon a designated index and that varies } \\
\text { directly with changes in the index. }\end{array}$ \\
\hline INV & Inverse Floating Rate & $\begin{array}{l}\text { Has an interest rate that resets periodically based upon a designated index and that varies } \\
\text { inversely with changes in the index. }\end{array}$ \\
\hline 10 & Interest Only & $\begin{array}{l}\text { Receives some or all of the interest payments made on the underlying securities or other assets } \\
\text { of the series trust but little or no principal. Interest Only classes have either a notional or a } \\
\text { nominal principal balance. A notional principal balance is the amount used as a reference to } \\
\text { calculate the amount of interest due on an Interest Only class. A nominal principal balance } \\
\text { represents actual principal that will be paid on the class. It is referred to as nominal since it is } \\
\text { extremely small compared to other classes. }\end{array}$ \\
\hline PO & Principal Only & Does not bear interest and is entitled to receive only payments of principal. \\
\hline Other & & $\begin{array}{l}\text { An "other" interest type. A catch-all for those CMOs that earn interest in a manner not captured } \\
\text { above. Examples include: has an interest rate that represents an effective weighted average } \\
\text { interest rate that may change from period to period (WAC), ascending and declining rates, etc. }\end{array}$ \\
\hline
\end{tabular}

*This is a partial list of CMO types used in this study. For a more complete list, see Hayre (1999). 
Table 2

Summary of Allocation Rules for Different Principal and Interest Types

\begin{tabular}{|l|l|l|}
\hline Allocation Type & Allocation Rule & Types \\
\hline Principal & Sequential & SEQ \\
\hline & Priority & $\begin{array}{l}\text { AD, NAS, PAC, PAC1, PAC2, } \\
\text { PAC3, SPP, SUP, TAC }\end{array}$ \\
\hline & Pro Rata & PT, NTL, STP \\
\hline Interest & Fixed (discount/premium) & FIX \\
\hline & Floater/Inverse floater & FLT, INV \\
\hline & Strip & IO, PO \\
\hline Principal/Interest & Accrual & Z \\
\hline
\end{tabular}

Table 3

Summary of Freddie Mac Multiclass Certificates, Series 4097

$\begin{array}{lrrrrr}\text { Type } & \text { Count } & \text { Min of Coupon } & \text { Max of Coupon } & \text { Min of Avg. Life } & \text { Max of Avg. Life } \\ \text { AD_SEQ_FIX } & 2 & 3.5 & 3.5 & 3.75 & 3.77 \\ \text { NPR_NPR } & 4 & 0 & 0 & 0 & 0 \\ \text { NTL_PAC_FIX_IO } & 1 & 3.5 & 3.5 & 2.61 & 2.61 \\ \text { NTL_PAC_INV_IO } & 4 & 5.9 & 5.9 & 2.26 & 2.76 \\ \text { NTL_PAC1_INV_IO } & 3 & 5.9 & 5.95 & 2.79 & 3.47 \\ \text { NTL_PT_FIX_IO } & 7 & 2.5 & 3 & 2.35 & 2.36 \\ \text { NTL_PT_INV_IO } & 10 & 5.75 & 5.9045 & 2.51 & 2.66 \\ \text { NTL_SEQ_FIX_IO } & 4 & 3 & 3.5 & 0.09 & 2.16 \\ \text { NTL_SEQ_INV_IO } & 5 & 5.85 & 5.95 & 1.54 & 1.98 \\ \text { PAC_FIX } & 40 & 1 & 6.5 & 2.26 & 10.97 \\ \text { PAC_FLT } & 4 & 0.6 & 0.6 & 2.26 & 2.76 \\ \text { PAC1_FIX } & 23 & 1 & 3 & 2.79 & 14.57 \\ \text { PAC1_FLT } & 3 & 0.55 & 0.6 & 2.79 & 3.47 \\ \text { PAC2_FIX } & 4 & 2.5 & 3 & 0.83 & 1.03 \\ \text { PAC3_FIX } & 5 & 2.5 & 3.5 & 0.6 & 0.71 \\ \text { PAC3_RTL_FIX } & 2 & 2.75 & 3 & 0.55 & 0.71 \\ \text { PT_FIX } & 56 & 1 & 6.5 & 2.35 & 2.66 \\ \text { PT_FLT } & 10 & 0.5955 & 0.75 & 2.51 & 2.66 \\ \text { PT_SEQ_FIX } & 6 & 1.5 & 3 & 2.34 & 2.58 \\ \text { SEQ_FIX } & 80 & 1 & 6.5 & 0.09 & 10.18 \\ \text { SEQ_FIX_Z } & 3 & 3 & 3.5 & 7.9 & 7.97 \\ \text { SEQ_FLT } & 5 & 0.55 & 0.65 & 1.54 & 1.98 \\ \text { SUP_FIX } & 7 & 2.5 & 3 & 0.19 & 0.56 \\ \text { SUP_FIX_Z } & 3 & 3 & 3.5 & 0.22 & 0.4 \\ \text { SUP_RTL_FIX } & 5 & 2.5 & 3 & 0.19 & \mathbf{1 4} \\ \text { Grand Total } & 296 & 0 & 6.5 & 0 & \end{array}$


Table 4

Agency CMO Sample by Principal and Interest Type

\begin{tabular}{|c|c|c|c|c|c|c|c|c|c|c|c|}
\hline \multirow[b]{2}{*}{ Principal Types } & \multirow{2}{*}{$\begin{array}{c}\text { Agency } \\
\text { Acronym }\end{array}$} & \multicolumn{9}{|c|}{ Interest Types } & \multirow[b]{2}{*}{ Totals } \\
\hline & & FIX & FIX_IO & FLT & FLT_IO & INV & INV_IO & Other & Other_IO & $\mathrm{PO}$ & \\
\hline Accelerating Senior & AS & 7 & & & & & & & & & 7 \\
\hline Accretion Directed & $A D$ & 791 & & 179 & & & & 12 & & 1 & 983 \\
\hline Bullet & BUL & 2 & & & & 1 & & & & & 3 \\
\hline Call & CALL & 1 & & & & & & 17 & & 1 & 19 \\
\hline Index & $X A C$ & 1 & & & & & & & & & 1 \\
\hline Non-Accelerating Senior & NAS & 37 & 1 & & & & & & & 3 & 41 \\
\hline Notional & NTL & & 208 & & 7 & & 175 & & 38 & & 428 \\
\hline Planned Amortization Class & PAC & 1529 & 59 & 123 & 7 & 71 & 79 & 1 & & 266 & 2,135 \\
\hline PAC1 & PAC1 & 616 & 28 & 34 & 10 & 12 & 23 & & & 87 & 810 \\
\hline PAC2 & PAC2 & 165 & & 7 & & 7 & & & & 1 & 180 \\
\hline PAC3 & PAC3 & 13 & & 4 & & 1 & 1 & & & & 19 \\
\hline Pass-Through & PT & 133 & 29 & 722 & 19 & 75 & 177 & 44 & 4 & 249 & 1,452 \\
\hline Pro-Rata Strip & STP & 2 & 3 & 7 & & 1 & & & & 1 & 14 \\
\hline Sequential & SEQ & 1505 & 62 & 115 & 3 & 13 & 29 & 9 & & 98 & 1,834 \\
\hline Shifting Payment Percentage & SPP & 18 & & 5 & & & & & & & 23 \\
\hline Support & SUP & 418 & 3 & 178 & 1 & 143 & 15 & 4 & & 70 & 832 \\
\hline Targeted Amortization Class & TAC & 65 & 2 & 48 & 3 & 82 & 14 & 1 & & 18 & 233 \\
\hline "Z" Accrual & Z & 999 & & & & & & & & & 999 \\
\hline Totals & & 6,302 & 395 & 1,422 & 50 & 406 & 513 & 88 & 42 & 795 & 10,013 \\
\hline
\end{tabular}


Table 5

Changes in Market Values +200 Basis Point Parallel Yield Curve Shift

\begin{tabular}{|c|c|c|c|c|c|c|c|c|c|}
\hline \multirow[b]{2}{*}{ Type } & \multirow[b]{2}{*}{ Count } & \multirow[b]{2}{*}{ Mkt Value } & \multicolumn{2}{|c|}{+200 basis points } & \multicolumn{5}{|c|}{ Quartiles } \\
\hline & & & Shift Mkt Value & Mkt Value $\Delta$ & Min & 25 & 50 & 75 & Max \\
\hline Accretion Directed Fixed & 791 & 106.15 & 99.09 & $-6.6 \%$ & $-24.4 \%$ & $-9.6 \%$ & $-6.1 \%$ & $-2.1 \%$ & $2.2 \%$ \\
\hline Accretion Directed Floating & 179 & 100.77 & 98.95 & $-1.8 \%$ & $-7.5 \%$ & $-2.6 \%$ & $-1.8 \%$ & $-1.2 \%$ & $22.6 \%$ \\
\hline Notional Fixed Interest Only & 204 & 22.55 & 29.34 & $46.9 \%$ & $-9.2 \%$ & $17.9 \%$ & $29.7 \%$ & $54.9 \%$ & $556.3 \%$ \\
\hline Notional Inverse Interest Only & 159 & 12.95 & 10.52 & $-14.7 \%$ & $-57.9 \%$ & $-25.5 \%$ & $-17.6 \%$ & $-10.2 \%$ & $100.3 \%$ \\
\hline PAC Fixed & 1,529 & 108.30 & 100.33 & $-7.2 \%$ & $-26.1 \%$ & $-11.2 \%$ & $-6.6 \%$ & $-1.9 \%$ & $2.9 \%$ \\
\hline PAC Fixed Interest Only & 56 & 25.18 & 33.35 & $56.8 \%$ & $-0.4 \%$ & $18.8 \%$ & $32.3 \%$ & $69.7 \%$ & $281.2 \%$ \\
\hline PAC Floating & 123 & 101.50 & 99.66 & $-1.8 \%$ & $-12.2 \%$ & $-2.3 \%$ & $-1.4 \%$ & $-0.5 \%$ & $0.8 \%$ \\
\hline PAC Inverse & 71 & 127.87 & 106.30 & $-16.4 \%$ & $-48.5 \%$ & $-20.4 \%$ & $-17.2 \%$ & $-11.5 \%$ & $1.5 \%$ \\
\hline PAC Inverse Interest Only & 51 & 18.75 & 16.05 & $-5.7 \%$ & $-35.0 \%$ & $-23.5 \%$ & $-15.1 \%$ & $-4.9 \%$ & $111.6 \%$ \\
\hline PAC Principal Only & 266 & 83.63 & 66.46 & $-21.9 \%$ & $-49.4 \%$ & $-28.6 \%$ & $-20.7 \%$ & $-13.5 \%$ & $-1.1 \%$ \\
\hline PAC1 Fixed & 616 & 107.96 & 99.82 & $-7.4 \%$ & $-21.5 \%$ & $-12.5 \%$ & $-6.5 \%$ & $-1.6 \%$ & $2.7 \%$ \\
\hline PAC1 Principal Only & 87 & 75.73 & 55.42 & $-28.8 \%$ & $-49.5 \%$ & $-40.2 \%$ & $-28.1 \%$ & $-20.0 \%$ & $-1.1 \%$ \\
\hline PAC2 Fixed & 165 & 101.44 & 92.69 & $-8.6 \%$ & $-19.3 \%$ & $-10.9 \%$ & $-9.0 \%$ & $-6.7 \%$ & $0.0 \%$ \\
\hline Pass-Through Fixed & 133 & 105.96 & 99.12 & $-6.4 \%$ & $-20.9 \%$ & $-7.6 \%$ & $-6.2 \%$ & $-3.8 \%$ & $1.4 \%$ \\
\hline Pass-Through Floating & 722 & 100.95 & 98.81 & $-1.8 \%$ & $-9.8 \%$ & $-2.9 \%$ & $-2.3 \%$ & $-1.7 \%$ & $240.9 \%$ \\
\hline Pass-Through Inverse & 75 & 118.83 & 98.83 & $-16.8 \%$ & $-46.6 \%$ & $-21.0 \%$ & $-15.8 \%$ & $-10.4 \%$ & $-0.6 \%$ \\
\hline Pass-Through Inverse Interest Only & 123 & 12.76 & 10.47 & $-15.7 \%$ & $-43.3 \%$ & $-23.0 \%$ & $-15.7 \%$ & $-10.6 \%$ & $93.4 \%$ \\
\hline Pass-Through Principal Only & 249 & 89.84 & 70.33 & $-22.0 \%$ & $-50.0 \%$ & $-24.6 \%$ & $-22.7 \%$ & $-18.7 \%$ & $-2.2 \%$ \\
\hline Sequential Fixed & 1,505 & 106.54 & 99.52 & $-6.5 \%$ & $-24.7 \%$ & $-10.0 \%$ & $-5.4 \%$ & $-1.5 \%$ & $3.3 \%$ \\
\hline Sequential Fixed Interest Only & 61 & 17.02 & 23.88 & $66.3 \%$ & $-2.1 \%$ & $27.3 \%$ & $58.5 \%$ & $85.7 \%$ & $296.9 \%$ \\
\hline Sequential Floating & 115 & 100.65 & 99.60 & $-1.0 \%$ & $-10.8 \%$ & $-1.5 \%$ & $-0.4 \%$ & $0.0 \%$ & $0.5 \%$ \\
\hline Sequential Principal Only & 98 & 88.46 & 73.38 & $-18.6 \%$ & $-67.3 \%$ & $-25.7 \%$ & $-14.6 \%$ & $-6.7 \%$ & $-0.3 \%$ \\
\hline Support Fixed & 418 & 101.25 & 92.06 & $-9.1 \%$ & $-25.2 \%$ & $-15.1 \%$ & $-8.3 \%$ & $-3.2 \%$ & $3.4 \%$ \\
\hline Support Floating & 178 & 100.98 & 98.39 & $-2.6 \%$ & $-10.0 \%$ & $-4.7 \%$ & $-2.4 \%$ & $-0.7 \%$ & $39.2 \%$ \\
\hline Support Inverse & 143 & 106.09 & 84.08 & $-21.0 \%$ & $-55.0 \%$ & $-31.2 \%$ & $-20.6 \%$ & $-12.2 \%$ & $113.9 \%$ \\
\hline Support Principal Only & 70 & 90.55 & 56.78 & $-37.9 \%$ & $-58.6 \%$ & $-44.3 \%$ & $-40.4 \%$ & $-34.4 \%$ & $-0.1 \%$ \\
\hline TAC Fixed & 65 & 104.21 & 98.92 & $-5.0 \%$ & $-21.3 \%$ & $-8.0 \%$ & $-5.2 \%$ & $-0.7 \%$ & $0.9 \%$ \\
\hline TAC Inverse & 82 & 110.69 & 97.81 & $-11.6 \%$ & $-33.4 \%$ & $-15.8 \%$ & $-12.7 \%$ & $-7.0 \%$ & $9.0 \%$ \\
\hline Z Accrual Bond Fixed & 999 & 112.04 & 96.16 & $-14.3 \%$ & $-35.4 \%$ & $-22.6 \%$ & $-12.4 \%$ & $-6.7 \%$ & $3.2 \%$ \\
\hline ALL & 9,333 & 98.71 & 90.22 & $-7.1 \%$ & $-67.3 \%$ & $-13.1 \%$ & $-5.8 \%$ & $-1.2 \%$ & $556.3 \%$ \\
\hline
\end{tabular}


Table 6

Volatility assumptions and correlation matrix for November 26, 2010

\begin{tabular}{|l|cc|c|c|cccccc|}
\multicolumn{1}{c}{ 1-wk } & \multicolumn{1}{c|}{ 3-mo } & \multicolumn{1}{c|}{ correlation matrix } \\
\hline & $\begin{array}{c}\text { Annual } \\
\text { Vol }\end{array}$ & $\begin{array}{c}\text { Mean } \\
\text { Reversion }\end{array}$ & STDEV & STDEV & IR level & IR slope & OAS & Refi & Turn & Vega \\
\hline IR level, & & & & & & & & & & \\
bp & 111.3 & 1.1 & 15.5 & 55.9 & 1 & 0 & 0 & 0 & 0 & 0 \\
IR slope & 0.7 & 0.0 & 0.1 & 0.4 & 0 & 1 & 0 & 0 & 0 & 0 \\
OAS, bp & 50 & 20 & 5.0 & 17.2 & 0 & 0 & 1 & 0 & 0 & 0 \\
Refi, \% & 30.2 & 1716 & 21.0 & 30.2 & 0 & 0 & 0 & 1 & -0.5 & 0 \\
Turn, \% & 16.1 & 4160 & 14.4 & 16.1 & 0 & 0 & 0 & -0.5 & 1 & 0 \\
Vega, \% & 20 & 10 & 2.9 & 10.4 & 0 & 0 & 0 & 0 & 0 & 1 \\
\hline
\end{tabular}

${ }^{*}$ Multiple of the selected pattern 
Table 7

Value at Risk (VaR) Decomposition

1-Week VaR by CMO Type Sorted by Average Total Risk

\begin{tabular}{|c|c|c|c|c|c|c|c|c|c|c|c|}
\hline \multirow[b]{2}{*}{ Type } & \multirow[b]{2}{*}{ Count } & \multicolumn{4}{|c|}{ ON AVERAGE } & \multicolumn{4}{|c|}{ WORST 95\%-tile } & \multirow[b]{2}{*}{ Worst/Avg } & \multirow{2}{*}{$\begin{array}{l}\text { minus IRR } \\
\text { AVERAGE }\end{array}$} \\
\hline & & RATE RISK & SPREAD RISK & PREPAY RISK & TOTAL & RATE RISK & SPREAD RISK & PREPAY RISK & TOTAL & & \\
\hline Sequential Fixed Interest Only & 61 。 & olll 5.52 & 0.13 & olll 7.54 & ooll 9.54 & oll 11.76 & ofl] 0.29 & Inll 15.18 & olll 18.63 & 1.95 & $-20.0 \%$ \\
\hline PAC Fixed Interest Only & 56 & olll 4.21 & 0.18 & olll 6.34 & ooll 7.74 & olll 9.26 & 0.36 & olll 14.22 & olll 16.68 & 2.16 & $-18.4 \%$ \\
\hline Notional Fixed Interest Only & 204 & olll 3.86 & 0.17 & , oll 5.80 & ooll 7.11 & olll 8.57 & ofld 0.31 & noll 14.81 & ooll 16.87 & 2.37 & $-19.2 \%$ \\
\hline PAC Inverse Interest Only & 51 & olll 2.08 & 0.10 & olll 6.66 & ooll 7.07 & olll 5.08 & ofl] 0.17 & olll 13.74 & olll 14.41 & 2.04 & $-7.6 \%$ \\
\hline Pass-Through Inverse Interest Only & 123 & olll 1.53 & 0.11 & 6.27 & olll 6.51 & oll 2.70 & 0.15 & 9.31 & ofll 9.30 & 1.43 & $-4.3 \%$ \\
\hline Notional Inverse Interest Only & 159 & olll 1.84 & 0.11 & , olll 5.93 & olll 6.33 & olll 3.95 & 0.17 & noll 11.62 & olll 11.88 & 1.88 & $-8.1 \%$ \\
\hline Support Principal Only & 70 & olll 2.73 & 0.09 & „nll 2.76 & olll 3.95 & olll 6.38 & 0.32 & 6.22 & olll 8.77 & 2.22 & $-32.4 \%$ \\
\hline PAC1 Principal Only & 87.0 & olll 2.67 & 0.34 & olll 1.69 & ofll 3.20 & olll 5.59 & 0.75 & olll 3.63 & olll 6.65 & 2.07 & $-45.7 \%$ \\
\hline PAC Principal Only & 266 & olll 1.84 & 0.24 & ॥ll] 1.14 & ofll 2.19 & olll 4.40 & 0.58 & „olll 2.68 & olll 5.15 & 2.35 & $-46.5 \%$ \\
\hline Sequential Principal Only & 98 & olll 1.57 & 0.19 & ॥ll] 1.01 & ofll 1.90 & olll 4.56 & 0.49 & olll 3.29 & olll 5.62 & 2.96 & $-48.8 \%$ \\
\hline Support Inverse & 143 & oll 1.14 & 0.09 & , 1.17 & olll 1.82 & olll 3.47 & 0.25 & 3.58 & ofll 4.76 & 2.61 & $-30.8 \%$ \\
\hline TAC Inverse & 82 & 0.56 & 0.06 & olll 1.58 & olll 1.77 & olll 1.76 & 0.17 & 6.17 & olll 6.38 & 3.61 & $-17.1 \%$ \\
\hline Pass-Through Principal Only & 249 & olll 1.41 & 0.15 & , IIl] 1.03 & ooll 1.76 & olll 2.55 & ofl] 0.26 & ,oll 1.77 & olll 3.08 & 1.75 & $-40.4 \%$ \\
\hline PAC Inverse & 71 & all 1.00 & 0.14 & oll] 1.24 & olll 1.73 & woll 2.34 & . 10l] 0.30 & olll 3.69 & oill 4.20 & 2.44 & $-28.5 \%$ \\
\hline Pass-Through Inverse & 75 & olll 1.00 & 0.15 & oll] 1.17 & olll 1.67 & olll 2.45 & . 10: 0.30 & 3.09 & olll 3.72 & 2.23 & $-30.5 \%$ \\
\hline Z Accrual Bond Fixed & 999 & oll 1.02 & 0.31 & 0.58 & oll 1.31 & olll 2.59 & 0.74 & 1.41 & olll 2.86 & 2.19 & $-37.1 \%$ \\
\hline PAC1 Fixed & 616 & 0.52 & 0.20 & 0.48 & 0.81 & olll 1.46 & ol] 0.50 & oll 0.92 & ooll 1.65 & 2.04 & $-25.5 \%$ \\
\hline PAC Fixed & 1529 ه & 0.51 & 0.18 & 0.44 & 0.76 & oll 1.45 & ofl] 0.46 & „oll] 0.87 & olll 1.65 & 2.17 & $-27.4 \%$ \\
\hline Support Fixed & 418 & 0.42 & 0.09 & 0.44 & 0.68 & oll 1.43 & . ofl] 0.32 & ॥ll] 1.27 & olll 1.88 & 2.76 & $-24.4 \%$ \\
\hline Accretion Directed Fixed & 791 ه & 0.43 & 0.16 & 0.40 & 0.68 & ofld 1.27 & of 0.41 & oll] 0.95 & ofll 1.52 & 2.24 & $-28.3 \%$ \\
\hline Sequential Fixed & 1505 & 0.44 & 0.16 & 0.38 & 0.67 & oll 1.31 & 0.41 & 0.75 & ofl] 1.45 & 2.18 & $-25.1 \%$ \\
\hline PAC2 Fixed & 165 & 0.33 & 0.11 & 0.48 & 0.65 & 0.99 & 0.33 & 1.07 & ofl] 1.40 & 2.16 & $-19.3 \%$ \\
\hline Pass-Through Fixed & 133 & 0.40 & . 0.14 & oldी 0.36 & 0.61 & 0.97 & . 0.31 & .oll] 0.79 & olll 1.16 & 1.91 & $-32.4 \%$ \\
\hline TAC Fixed & 65 & 0.28 & 0.09 & 0.38 & 0.54 & 0.92 & 0.29 & „Ill] 0.89 & ofl] 1.23 & 2.29 & $-21.1 \%$ \\
\hline Support Floating & 178 。 & 0.17 & ofl] 0.11 & 0.19 & 0.31 & ofl 0.56 & 0.35 & 0.69 & ofl] 0.93 & 3.06 & $-22.2 \%$ \\
\hline Pass-Through Floating & 722 & 0.16 & 0.17 & 0.10 & 0.28 & olll 1.54 & . 10l] 0.24 & וll] 0.97 & olll 1.89 & 6.86 & $-17.6 \%$ \\
\hline PAC Floating & 123 & 0.12 & , 0.18 & It) 0.09 & 0.25 & 10 0.41 & . 0.42 & 0.25 & 0.62 & 2.43 & $-13.3 \%$ \\
\hline Accretion Directed Floating & 179 & 0.12 & 0.15 & ofl] 0.08 & 0.22 & 0.34 & . 10l] 0.30 & 0.26 & 0.51 & 2.29 & $-17.2 \%$ \\
\hline Sequential Floating & 115 & 0.07 & .01] 0.11 & 0.06 & 0.15 & 0.28 & . Ifl] 0.30 & 0.21 & 0.46 & 2.99 & $-8.7 \%$ \\
\hline ALL & 9333 & 0.79 & oflी 0.18 & 0.90 & ofld 1.33 & 3.09 & 0.47 & olll 4.56 & olll 5.52 & 4.15 & $-26.6 \%$ \\
\hline
\end{tabular}

Signal codes

\begin{tabular}{|c|c|c|}
\hline$>1.5$ & ollî́ & Highest \\
\hline bet 0.75 and 1.5 & oll? & \\
\hline 0.375 and 0.75 & ill & \\
\hline below 0.375 & o & Lowest \\
\hline
\end{tabular}


Table 8

Value at Risk (VaR) Decomposition

3-Month VaR by CMO Type Sorted by Average Total Risk

\begin{tabular}{|c|c|c|c|c|c|c|c|c|c|c|c|c|c|c|c|}
\hline \multirow{3}{*}{$\begin{array}{l}\text { Type } \\
\text { Sequential Fixed Interest Only }\end{array}$} & \multirow{3}{*}{$\begin{array}{c}\text { Count } \\
61\end{array}$} & \multicolumn{6}{|c|}{ ON AVERAGE } & \multicolumn{6}{|c|}{ UP TO } & \multirow{3}{*}{$\begin{array}{c}\text { Worst/Avg } \\
1.96\end{array}$} & \multirow{3}{*}{$\begin{array}{c}\text { minus IRR } \\
\text { AVERAGE } \\
-48.8 \%\end{array}$} \\
\hline & & \multirow{2}{*}{$\begin{array}{l}\text { IR Risk } \\
\text { II } 18.94\end{array}$} & \multirow{2}{*}{\multicolumn{2}{|c|}{$\begin{array}{l}\text { OAS Risk } \\
0.45\end{array}$}} & \multicolumn{2}{|c|}{ Prepay Risk } & \multirow{2}{*}{$\begin{array}{l}\text { TOTAL } \\
\text { oll } 22.33\end{array}$} & \multirow{2}{*}{$\begin{array}{l}\text { IR Risk } \\
\text { olll } 39.62\end{array}$} & \multicolumn{2}{|c|}{ OAS Risk } & \multicolumn{2}{|c|}{ Prepay Risk } & \multirow{2}{*}{$\begin{array}{l}\text { TOTAL } \\
\text { ofll } 43.79\end{array}$} & & \\
\hline & & & & & ,oll & 10.72 & & & ol] & 1.00 & olll & 22.17 & & & \\
\hline PAC Fixed Interest Only & 56 oll & 14.68 & all & 0.60 & , oll & 8.94 & olll17.59 & olll 30.92 & al] & 1.24 & olll & 20.71 & olll 36.25 & 2.06 & $-47.9 \%$ \\
\hline Notional Fixed Interest Only & 204 oll & 13.73 & ol? & 0.57 & , nll & 7.58 & olll 16.20 & oll| 29.45 & al] & 1.08 & olll & 20.84 & oll| 35.14 & 2.17 & $-52.4 \%$ \\
\hline Support Principal Only & 70 oll & 12.66 & oll & 0.32 & , IIl] & 3.90 & olll 13.35 & olll 25.87 & al] & 1.10 & olll & 8.87 & olll 27.12 & 2.03 & $-71.2 \%$ \\
\hline PAC Inverse Interest Only & 51 oll & 8.10 & of & 0.35 & ,oll & 9.67 & olll 13.10 & olll 18.89 & ol] & 0.59 & olll & 20.10 & oll| 26.36 & 2.01 & $-26.0 \%$ \\
\hline Notional Inverse Interest Only & 159 oll & \| 6.54 & aी? & 0.36 & ,oll & 8.58 & olll11.35 & oll 14.24 & ol] & 0.58 & olll & 17.10 & . IIll 20.45 & 1.80 & $-24.1 \%$ \\
\hline Pass-Through Inverse Interest Only & 123 oll & || 5.96 & ofl] & 0.37 & ,oll & 9.09 & olll11.26 & olll 10.91 & n? & 0.50 & olll & 13.76 & olll 14.73 & 1.31 & $-19.3 \%$ \\
\hline PAC1 Principal Only & 87 oll & || 9.78 & oll & 1.17 & oll & 2.17 & olll10.11 & oll 20.00 & oll & 2.58 & olll & 4.65 & oll| 20.63 & 2.04 & $-74.4 \%$ \\
\hline PAC Principal Only & 266 oll & || 6.82 & , 10 & 0.84 & old & 1.50 & ,oll 7.05 & olll 15.89 & ol] & 1.98 & oll & 3.52 & oll 16.36 & 2.32 & $-74.0 \%$ \\
\hline Sequential Principal Only & 98 oll & || 5.92 & oll] & 0.67 & 1010 & 1.32 & olll 6.12 & olll 16.69 & ol] & 1.69 & oolll & 4.17 & oill 17.28 & 2.83 & $-75.4 \%$ \\
\hline Pass-Through Principal Only & 249 oll & || 5.68 & oll? & 0.51 & 10 ll & 1.40 & olll 5.89 & olll 9.99 & ol] & 0.90 & oll & 2.42 & olll 10.27 & 1.74 & $-73.8 \%$ \\
\hline Support Inverse & 143 oll & || 5.13 & oll? & 0.31 & 10 ll & 1.63 & olll 5.74 & oll 14.51 & ofl] & 0.87 & ooll & 5.09 & olll 14.95 & 2.60 & $-54.9 \%$ \\
\hline PAC Inverse & 71 oll & 3.88 & all & 0.48 & 10 ll & 1.80 & olll 4.57 & olll 8.90 & of & 1.02 & ooll & 5.35 & olll 9.92 & 2.17 & $-52.0 \%$ \\
\hline Pass-Through Inverse & 75 oll & 3.83 & all? & 0.50 & 10 ?ी & 1.69 & olll 4.44 & olll 8.94 & of & 1.02 & olll & 4.51 & olll 9.61 & 2.16 & $-55.4 \%$ \\
\hline Z Accrual Bond Fixed & 999 oll & 3.92 & all & 1.09 & 1000 & 0.82 & olll 4.26 & olll 9.80 & oll & 2.54 & oll & 2.04 & olll 10.14 & 2.38 & $-55.4 \%$ \\
\hline TAC Inverse & $82 \mathrm{oll}$ & 2.43 & ofl] & 0.22 & , IIl & 2.30 & .10l 3.74 & olll 6.68 & of & 0.59 & ooll & 9.00 & olll 10.96 & 2.93 & $-36.0 \%$ \\
\hline PAC1 Fixed & 616 oll & 2.01 & ofl] & 0.68 & oll & 0.69 & oll 2.35 & olll 5.47 & ol] & 1.73 & oll & 1.33 & olll 5.71 & 2.43 & $-41.9 \%$ \\
\hline Support Fixed & 418 oll & 2.11 & ol? & 0.31 & oll & 0.59 & oll 2.35 & olll 6.95 & of & 1.09 & oll & 1.75 & olll 7.14 & 3.04 & $-45.2 \%$ \\
\hline PAC Fixed & 1529 ol & 1.93 & ofl] & 0.61 & 10 ? & 0.64 & oll 2.22 & olll 5.41 & al] & 1.60 & ol & 1.26 & olll 5.65 & 2.55 & $-44.3 \%$ \\
\hline Accretion Directed Fixed & 791 ol & 1.72 & oll? & 0.54 & oll & 0.57 & 2.00 & olll 4.85 & al] & 1.40 & all & 1.33 & olll 5.07 & 2.54 & $-45.5 \%$ \\
\hline Sequential Fixed & 1505 ol & 1.69 & oll & 0.54 & ,10 & 0.54 & 1.96 & olll 4.93 & ol] & 1.41 & ol? & 1.08 & olll 5.12 & 2.62 & $-41.7 \%$ \\
\hline PAC2 Fixed & 165 & 1.61 & ofl] & 0.38 & 10 & 0.64 & 1.91 & olll 4.63 & oll & 1.13 & all & 1.40 & olll 4.79 & 2.51 & $-41.9 \%$ \\
\hline Pass-Through Fixed & 133 & 1.54 & all & 0.50 & 10 lी & 0.51 & of 1.77 & oll 3.65 & all & 1.06 & oll & 1.13 & oll 3.82 & 2.16 & $-49.8 \%$ \\
\hline TAC Fixed & 65.0 & 1.15 & oll & 0.32 & olी & 0.55 & 1.44 & oll 3.61 & oll & 1.01 & al? & 1.29 & oll 3.83 & 2.65 & $-36.2 \%$ \\
\hline Support Floating & 178 & 0.81 & oll & 0.38 & ,10ी & 0.27 & 1.00 & oll 2.80 & oll & 1.22 & oll & 1.00 & oll 3.16 & 3.16 & $-40.2 \%$ \\
\hline Pass-Through Floating & 722 of & 0.62 & oll & 0.58 & olी & 0.15 & 0.92 & olll 5.30 & ol] & 0.83 & all & 1.40 & olll 5.73 & 6.22 & $-22.9 \%$ \\
\hline PAC Floating & 123 & 0.48 & oll & 0.63 & oll] & 0.14 & 0.84 & of 1.59 & ol] & 1.44 & all & 0.36 & oll 2.14 & 2.54 & $-16.9 \%$ \\
\hline Accretion Directed Floating & 179 & 0.47 & oll? & 0.50 & all] & 0.12 & 0.75 & of 1.39 & ol] & 1.05 & all & 0.38 & 1.72 & 2.30 & $-23.9 \%$ \\
\hline Sequential Floating & 115 & 0.26 & oll? & 0.39 & 口ीl] & 0.09 & .1] 0.49 & of 1.12 & oll] & 1.04 & oll] & 0.30 & 1.55 & 3.16 & $-10.9 \%$ \\
\hline ALL & 9333 oll & 3.02 & alी & 0.60 & , 10 & 1.27 & 3.58 & 11.30 & of & 1.60 & ollll & 6.48 & 13.06 & 3.64 & $-44.3 \%$ \\
\hline
\end{tabular}


Figure 1

Historical Risk-Neutral Refinancing and Turnover Scales in $\mathbf{2 0 1 0}$

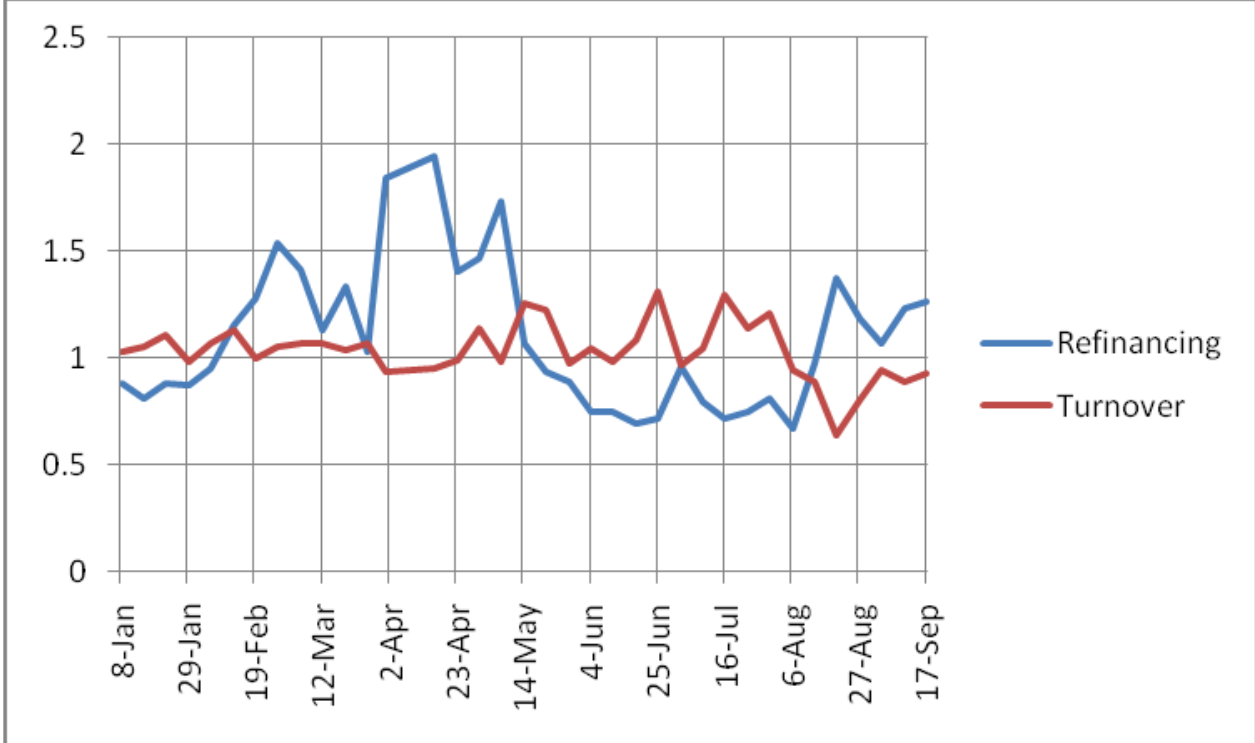

Figure 2

$\sigma(t) / \sigma(1)$ Ratio as a Function of $a$

\begin{tabular}{|r|l|l|l|l|}
\hline 1.6 & & & & \\
\hline 1.4 & & & & \\
\hline 1.2 & & & & \\
\hline \\
\hline
\end{tabular}

